\title{
MICROLEAKAGE EVALUATION OF MODIFIED MINERAL TRIOXIDE AGGREGATE EFFECT TOWARD MARGINAL ADAPTATION ON CERVICAL DENTIN PERFORATION
}

\author{
FERYARISKA DEWI, DINI ASRIANTI*, ANGGRAINI MARGONO
}

Department of Conservative Dentistry, Faculty of Dentistry, Universitas Indonesia, Jakarta, Indonesia. Email: dini.rz@gmail.com Received: 16 September 2017, Received and Accepted: 03 October 2017

ABSTRACT

Objective: To analyze the marginal adaptation of conventional MTA (ProRoot $® M T A)$ and modified MTA (MTA Flow ${ }^{\mathrm{TM}}$ ) on perforated dentin.

Methods: Forty specimens of human's premolar teeth with lateral perforations were sealed by conventional MTA ( $\mathrm{n}=20$ ) and modified MTA ( $=20$ ). After 24 hours, the specimens were immersed in Indian ink for 24 hours, then embedded in resin and sectioned longitudinally in mesial-distal direction. The score of microleakage was determined using stereo microscope (SteREO Discovery. V12, Carl Zeiss) with 20x magnification. Statistical analysis was done by Chi Square $(\mathrm{p}<0,05)$.

Results: Less microleakage score (0,5-1mm) was detected in modified MTA (25\%) compared to conventional MTA (45\%), although not statistically significant.

Conclusion: Microleakage were detected in both conventional and modified MTA as material for cervical dentin perforation treatment, although modified-MTA group showed less microleakage score.

Keywords: Perforation, Mineral trioxide aggregate, Modified mineral trioxide aggregate, Microleakage, Marginal adaptation.

(C) 2017 The Authors. Published by Innovare Academic Sciences Pvt Ltd. This is an open access article under the CC BY license (http://creativecommons. org/licenses/by/4. 0/) DOI: http://dx.doi.org/10.22159/ijap.2017.v9s2.03

\section{INTRODUCTION}

Perforation is a procedural accident that can occur during endodontic treatment to create communications between the root canal system and supporting tissues of the teeth. Sealing the perforation defect is an important step in limiting bacterial contamination [1]. Among the various available materials to seal perforations, MTA is the optimal choice for the procedure due to its biocompatibility, great sealing ability and adaptation to the dentinal wall, high $\mathrm{pH}$, and ability to release calcium ions [2-4]. MTA applications can also induce hard tissue formation (dentin, cementum, and bone) and can facilitate periodontal tissue regeneration [2-5]. Pace et al. reported that $90 \%$ of perforation treatments using MTAs show periodontal and bone healing after 6 months, visible through the decrease in radiolucency in X-ray photos [5]. The material is not without disadvantages; however, namely, discoloration, lengthy setting times, and difficulty in handling $[2,4]$.

Over time, modifications have been made to improve MTAs' undesirable properties. MTA discoloration was resolved with the release of white MTA (WMTA) in 2002, which contained less iron than the first version, gray MTA (GMTA), marketed originally in 1998 [3]. However, most marketed MTA products still have long setting times of typically 3-4 h $[1,2,4]$. New MTA-based materials, marketed under the name MTA Flow $^{\mathrm{TM}}$ (Ultradent, South Jordan, UT), have also been developed to have smaller particle sizes. These are made up of powder and gel components with a particle size of powder at $<10 \mu \mathrm{m}$. The mean particle size of the conventional ProRoot ${ }^{\circledR}$ MTA (Dentsply, Tulsa) is $10 \mu \mathrm{m}$, in which all particles are smaller than $50 \mu \mathrm{m}$ [6]. Komabayasi et al. (2008) observed that the particle sizes of ProRoot ${ }^{\circledR}$ MTA (Dentsply, Tulsa) and MTA Angelus $®$ (Angelus, Brazil) ranged between 1.5 and $160 \mu \mathrm{m}$, with the percentage of particles between 6 and $10 \mu \mathrm{m}$ at $73 \%$ for ProRoot ${ }^{\circledR}$ MTA (Dentsply, Tulsa) and 53\% for MTA Angelus® (Angelus, Brazil) [7].

MTA Flow ${ }^{\mathrm{TM}}$ (Ultradent, South Jordan, UT)'s basic materials and properties resemble those of conventional MTAs (e.g., they have the same indications because they share the same active ingredient) [8].
The possible advantages of MTA Flow ${ }^{\mathrm{TM}}$ (Ultradent, South Jordan, UT) over a conventional MTA have yet to be researched in depth, however. Thus, it is necessary to conduct further analysis of MTA modifications, particularly in regards to the material's marginal adaptation. The aim of this study, therefore, is to analyze the differences in marginal adaptation between conventional and modified MTAs through microleakage evaluation in perforation treatments.

\section{METHODS}

Forty specimens of extracted human premolar teeth with no caries, fillings, crowns, root defects, or history of endodontic treatment were used for the present study. All teeth were kept moist before and during the experiment. The specimens were prepared through access opening and lateral perforation simulation. Perforations $2 \mathrm{~mm}$ in diameter were created by inserting a diamond round bur at $1 \mathrm{~mm}$ under the cementoenamel junction (CEJ) to penetrate the proximal wall. The specimens were then divided randomly into two groups of 20 specimens. Those in the first group were sealed by a conventional MTA (ProRoot $®$ MTA, Dentsply), and those in the second group were sealed by a modified MTA (MTA Flow ${ }^{\mathrm{TM}}$, Ultradent, South Jordan, UT). MTA manipulations were performed according to the manufacturer's instructions (powder: liquid ratio 3:1 for the first group and 2:2 for the second group); then, access cavity was sealed by glass ionomer cement (GIC) (GIC Fuji IX ${ }^{\mathrm{TM}}$, GC Corp Inc, USA). A dental loupe with $\times 3.0$ magnification was used by the operator in all the procedures.

After $24 \mathrm{~h}$ in a $37^{\circ} \mathrm{C}$ incubator, the specimens were coated with nail polish, leaving $1 \mathrm{~mm}$ around the restoration at the proximal wall. The specimens were immersed in India ink for $24 \mathrm{~h}$, then embedded in resin and sectioned longitudinally in a mesial-distal direction (Struers-Accutom-2). Microleakage scores were determined by measuring the depth of the ink's penetration along the restorations using a stereomicroscope (SteREO Discovery, V12, Carl Zeiss) with $\times 20$ magnification. Statistical analyses were performed through Chi-square tests ( $\mathrm{p}<0.05)$ using SPSS 20.0 software. A scanning electron microscope 
(SEM) and energy dispersive spectroscopy (EDS) were applied to each group to observe their marginal adaptation (physical properties) and mineral release (chemical properties).

\section{RESULTS}

Microleakage data were obtained by measuring India ink penetration with a stereomicroscope $(\times 20$ magnification). Microleakage scores were determined as $0=$ no leakage; $1=$ leakage ranging between 0 and $0.5 \mathrm{~mm} ; 2$ = leakage ranging between 0.5 and $1 \mathrm{~mm}$; and $3=$ leakage more than $1 \mathrm{~mm}$. The microscopic imaging of India ink penetration in Group 1 (conventional MTA) and Group 2 (modified MTA) was shown in Figs. 1 and 2

Table 1 summarizes that $30 \%$ of Group 1 and $40 \%$ of Group 2 had no leakage (score 0 ), 25\% of Group 1 and 35\% of Group 2 had scores of 1 , $45 \%$ of Group 1 and $25 \%$ of Group.

2 had scores of 2, and neither group contained scores of 3 . The Chi-square statistical analysis revealed no statistically substantial differences in microleakage scores between the conventional and modified MTAs $(\mathrm{p}=0.414)$, as shown in Table 1 . SEM imaging $(\times 200$ magnification $)$ revealed a gap between dentin and materials in both the conventional and modified MTAs (see Figs. 3 and 4). The EDS results confirmed that calcium ion release was higher in the modified MTA group (mean: $10.26 \%$ ) than in the conventional MTA group (mean: $8.9 \%$ ).

\section{DISCUSSION}

The India ink penetration revealed gaps or spaces between the dentinal wall of the root canal and sealant material in both the samples with conventional MTA and modified MTA. Leakages of varying degrees (i.e. different scores) were observed on the outlines of the longitudinal cuts on some samples, as shown in Table 1. Examination of the results shown in Table 1 showed that the largest number of those using the conventional MTA as their sealant for perforation scored a $2(45 \%)$, with leakage ranging between 0.5 and $1 \mathrm{~mm}$.

In the modified MTA group, the samples with scores of 0 (meaning no leakage) formed the largest result group (40\%), followed by those with scores of 1 with leakage ranging between 0 and $0.5 \mathrm{~mm}$ (35\%). These results indicate that less microleakage occurred in the modified MTA group than in the conventional MTA group.

This result is largely due to the particle size of the modified MTA, which was homogenous and smaller than $10 \mu \mathrm{m}$.

This falls in line with research conducted by Reyes-Carmona et al., who concluded that material with more homogenously sized particles will yield higher mechanical binding [9].

The authors asserted that smaller particle sizes also minimize spacing between particles, increase surface area, and better interlock powder particles to improve integrity, making the material more resistant to liquid penetration (Fig. 5) [2,10].

These smaller particle sizes also take on a pasta-like consistency that is much easier to apply than conventional MTAs that are characterized by a granular, sand-like texture $[7,9]$. The statistical Chi-square testing revealed no substantial differences in microleakage between the conventional and modified MTAs used as sealants for perforation. This result is similar to that in research by Dimitrova et al., on eight silicate calcium-based materials (MTA Angelus ${ }^{\circledR}$ [Angelus, Brazil], ProRoot MTA ${ }^{\circledR}$ [Dentsply, Tulsa], Aureoseal ${ }^{\circledR}$ [OGNA, Italy], Bio-Aggregate ${ }^{\circledR}$ [Diadent, Canada], Biodentin ${ }^{\circledR}$ [Septodont, USA], and Portland cements), which exhibited 5.62-7.28 $\mu \mathrm{m}$ leakage gaps between the material and dentin.

In this research, the smallest gap was observed on Bio-Aggregate ${ }^{\circledR}$ (Diadent, Canada) material and the biggest gap on other Biodentin ${ }^{\circledR}$ (Septodont, USA) but overall there were no statistical differences
Table 1: Microleakage score distribution in conventional and modified MTA groups

\begin{tabular}{llllll}
\hline \multirow{2}{*}{ Materials } & \multicolumn{4}{c}{ Microleakage scores (\%) } & \multirow{2}{*}{$\mathbf{p}$} \\
\cline { 2 - 5 } & $\mathbf{0}$ & $\mathbf{1}$ & $\mathbf{2}$ & $\mathbf{3}$ & \\
\hline Conventional MTA (n=20) & $6(30)$ & $5(25)$ & $9(45)$ & $0(0)$ & 0.414 \\
Modified MTA (n=20) & $8(40)$ & $7(35)$ & $5(25)$ & $0(0)$ & \\
\hline
\end{tabular}

MTA: Mineral trioxide aggregate
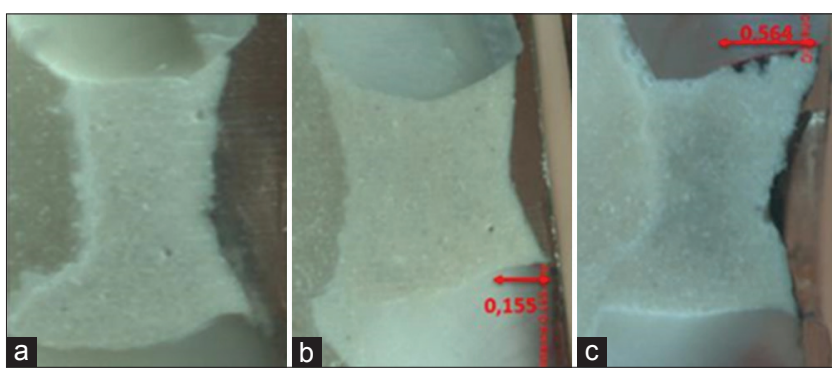

Fig. 1: Stereomicroscope pictures of conventional mineral trioxide aggregate group (a) score 0 , (b) score 1 , and (c) score 2

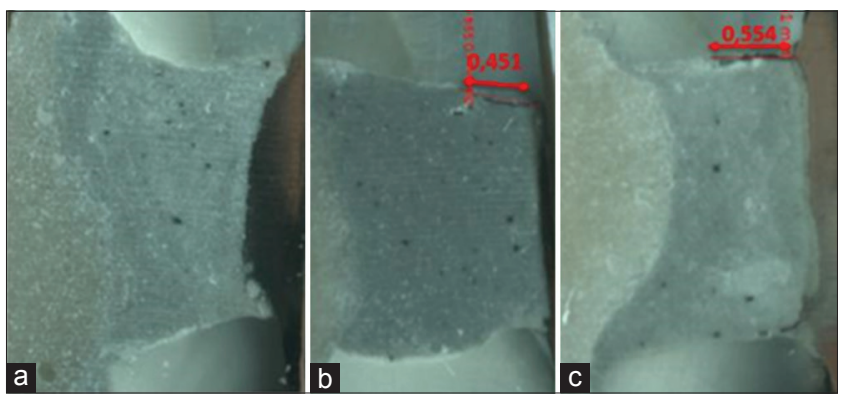

Fig. 2: Stereomicroscope pictures of modified mineral trioxide aggregate group (a) score $\mathbf{0}$, (b) score 1 , and (c) score 2

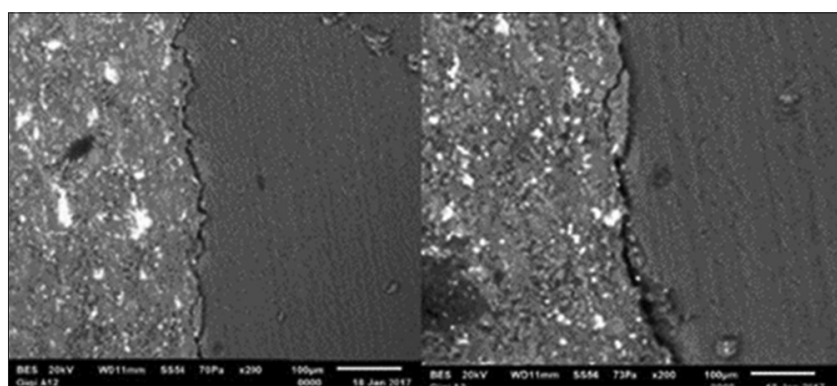

Fig. 3: Scanning electron microscope pictures $(\times 200)$ of longitudinally sectioned specimens with a gap between the dentin and conventional mineral trioxide aggregate

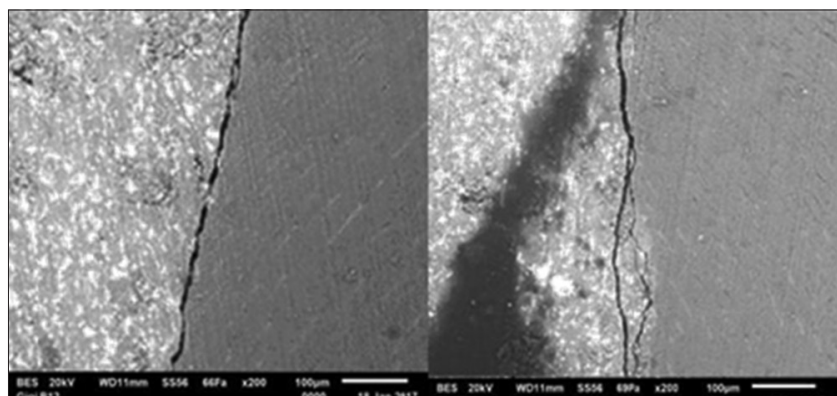

Fig. 4: Scanning electron microscope pictures $(\times 200)$ of longitudinally sectioned specimens with a gap between the dentin and modified mineral trioxide aggregate 


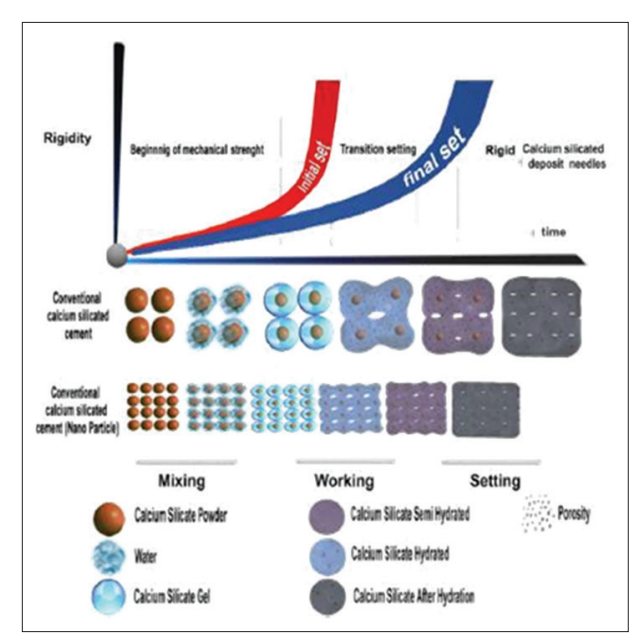

Fig. 5: Schematic figure of the mixing, working, and setting phases of calcium silicate cement. Materials with smaller size particles show less porosity than materials with large particles $[10,16]$.

among the samples [11]. The present research used the conventional ProRoot ${ }^{\circledR}$ MTA (Dentsply, Tulsa) on the first group, as this material is the current standard for treating perforation, and the modified MTA Flow $^{\mathrm{TM}}$ (Ultradent, South Jordan, UT), with its more homogenously sized particles at $<10 \mu \mathrm{m}$, on the second group.

In the present study, the modified MTA was observed to have a better consistency, making it easier to apply as well as a faster setting time of $15 \mathrm{~min}$. Indeed, after a mere $5 \mathrm{~min}$, the cement layer was able to be rinsed and dried without dissolving [8]. This faster setting time was due to the modified MTA's smaller particle size than that of the conventional MTA. This is in line with a study conducted by Saghiri et al., who shrunk a WMTA to make it more reactive. The smaller size meant more contacted surface, thus speeding up the setting time from $43 \pm 2 \mathrm{~min}$ to $6 \pm 1 \mathrm{~min}$. This eliminated the need to wash the outer layer of the MTA [2]. According to the literature, MTAs are desirable as perforation sealants because of the difficulty in isolating the working condition and the risk of blood and gingival fluid overflowing after application.

The dye penetration method was used to make microleakages observable in the present study. Sample teeth were immersed in coloring dye for a certain amount of time, then cut and observed at the marginal level between tooth and material. The dye used for this method was India ink with a particle diameter of $\leq 3 \mu \mathrm{m}$, smaller than the diameter of the bacteria found inside the canal spaces of the sample teeth [12]. Coloration on the marginal level of a sample tooth meant the presence of a microleakage. Verissimo and Fabinelli described dye penetration as the most common method for such procedures because of its easy application and lack of chemical reactions [12].

Under moist conditions, an MTA will initiate physical binding with dentin by forming a micromechanical tag-like structure in the dentinal tubules as well as chemical binding by forming an amorphous structure of silicate calcium with the dentinal wall. It also induces the formation of solid tissue surrounding the MTA [2]. This mirror study conducted by Dreger et al. in which MTA and Portland cement leased into the tissue calcium and phosphate ions capable of stimulating mineral deposition in the cement-dentin interface and in the interior of the dentinal tubules [13]. Continuous precipitation of calcium and phosphate ions causes hydroxyapatite to form on the interfacial layer and eventually bond biologically with the dentinal wall, which also has hydroxyapatite as its main structure [14]. Bird et al., who evaluated the ability of MTAs to penetrate human dentinal tubules, concluded that physiochemical reactions initiate the gradual formation of hydroxyapatite between an MTA and dentin, improving the MTA's sealing ability and biocompatibility [6]. These results all demonstrate that MTAs with smaller particle sizes and a more fluid consistency can better fill the irregularities of a dentinal wall to minimize gaps and that this can be done even faster with hydroxyapatite formation. Further, a WMTA modified by Saghiri et al. had nanoscale-sized particles that increased the calcium ion release significantly, affecting hard tissue regeneration to a high degree [10]. Calcium ions also influence tissue mineralization by fastening cell proliferation when present in large quantities [15]. The modified MTA in the present study demonstrated improved hard tissue regeneration potential (as shown in the results of the EDS tests), confirming that calcium ion release is higher in modified MTAs.

The SEM images presented in Figs. 3 and 4 show the gaps in both material groups. The calcium and phosphate ion precipitation had not yet maximized for sealing, as the observation took place $24 \mathrm{~h}$ after the MTA was applied. Kouzmanova made the same observation of such gaps $24 \mathrm{~h}$ after applying a silicate calcium-based material, including an MTA, to a bifurcation perforation [11]. Another study by Sarkar showed that bonding between an MTA and dentin will form a perfect seal over such gaps as an interfacial layer consisting of a new hydroxyapatite composition once 2 months has elapsed since MTA application to the canal space [14]. In short, the findings in the literature and in the present study indicate that modification increases not only the physical but also the chemical properties of an MTA. This process is driven by increases in marginal adaptation and ion calcium release as observed found in the present study.

\section{CONCLUSIONS}

Microleakages were detected in both conventional and modified MTAs used as materials for treating cervical dentin perforations, though the modified MTA group exhibited slightly lower microleakage scores.

\section{ACKNOWLEDGMENT}

The publication of this manuscript is supported by the Directorate of Research and Community Engagement of the Universitas Indonesia.

\section{REFERENCES}

1. Torabinejad M, Johnson JD. Procedural accidents. In: Endodontics: Principles and Practice. $5^{\text {th }}$ ed. St. Louis: Elsevier-Health Sciences Division; 2014. p. 338-43

2. Camilleri J. Mineral Trioxideaggregate in Dentistry from Preparation to Application. London: Springer; 2014

3. Naik RM, Pudakalkatti PS, Hattarki SA. Can MTA be: Miracle trioxide aggregate? J Indian Soc Periodontol 2014;18:5-8.

4. Srinivasan V, Waterhouse P, Whitworth J. MTA in Dentistry. New York: Springer. 2014.

5. Pace R, Giuliani V, Pagavino G. MTA as repair material for furcal perforation: Case series. J Endod 2008;34:1130-3.

6. Bird DC, Komabayashi T, Guo L, Opperman LA, Spears R. In vitro evaluation of dentinal tubule penetration and biomineralization ability of a new root-end filling material. J Endod 2012;38:1093-6.

7. Komabayashi T, Spångberg LS. Comparative analysis of the particle size and shape of commercially available MTAs and Portland cement: A study with a flow particle image analyzer. J Endod 2008;34:94-8.

8. Ultradent Product Inc. New Product Release International MTA Flow Repair Cement. MTA Flow Man Kit. South Jordan, UT: Ultradent Product Inc; 2016.

9. Reyes-Carmona JF, Felippe MS, Felippe WT. The biomineralization ability of MTA and Portland cement on dentin enhances the push-out strength. J Endod 2010;36:286-91.

10. Saghiri MA,Asatourian A, Orangi J, Lotfi M, Soukup JW, Garcia-Godoy F, et al. Effect of particle size on calcium release and elevation of $\mathrm{pH}$ of endodontic cements. Dent Traumatol 2015;31:196-201

11. Dimitrova I, Kouzmanova Y. Marginal adaptation of calcium silicatebase materials used in furcal perforartionrepair: A comparative in vitro study. Int J Sci Res 2015;4:750-75.

12. Veríssimo DM, do Vale MS. Methodologies for assessment of apical and coronal leakage of endodontic filling materials: A critical review. J Oral Sci 2006;48:93-8.

13. Dreger LA, Felippe WT, Reyes-Carmona JF, Felippe GS, Bortoluzzi EA, Felippe MC. MTA and Portland cement promote biomineralization in vivo. J Endod 2012;38:324-9. 
14. Sarkar NK, Caicedo R, Ritwik P, Moiseyeva R, Kawashima I. Physicochemical basis of the biologic properties of MTA. J Endod 2005;31:97-100.

15. Misra P, Bains R, Loomba K, Singh A, Sharma VP, Murthy RC, et al. Measurement of $\mathrm{pH}$ and calcium ions release from different calcium hydroxide pastes at different intervals of time: Atomic spectrophotometric analysis. J Oral Biol Craniofac Res 2017;7:36-41.

16. Saghiri MA, Asgar K, Lotfi M, Garcia-Godoy F. Nanomodification of MTA for enhanced physiochemical properties. Int Endod J 2012;45:979-88. 